\title{
Comparison of prokaryotic community structure from Mediterranean and Atlantic saltern concentrator ponds by a metagenomic approach
}

\author{
Ana B. Fernández ${ }^{1}$, Blanca Vera-Gargallo ${ }^{1}$, Cristina Sánchez-Porro ${ }^{1}$, Rohit Ghai ${ }^{2}$, R. Thane Papke ${ }^{3}$, \\ Francisco Rodriguez-Valera ${ }^{2}$ and Antonio Ventosa ${ }^{1 *}$ \\ ${ }^{1}$ Department of Microbiology and Parasitology, Faculty of Pharmacy, University of Sevilla, Sevilla, Spain \\ ${ }^{2}$ Evolutionary Genomics Group, Departamento de Producción Vegetal y Microbiología, Universidad Miguel Hernández, San Juan de Alicante, Alicante, Spain \\ ${ }^{3}$ Department of Molecular and Cell Biology, University of Connecticut, Storrs, CT, USA
}

\section{Edited by:}

Jesse Dillon, California State

University, Long Beach, USA

Reviewed by:

Eric E. Allen, Scripps Instituion of

Oceanography, USA

Jesse Dillon, California State

University, Long Beach, USA

*Correspondence:

Antonio Ventosa, Department of Microbiology and Parasitology,

Faculty of Pharmacy, University of Sevilla, Calle Profesor García

González 2, 41012 Sevilla, Spain

e-mail:ventosa@us.es
We analyzed the prokaryotic community structure of a saltern pond with $21 \%$ total salts located in Isla Cristina, Huelva, Southwest Spain, close to the Atlantic ocean coast. For this purpose, we constructed a metagenome (designated as IC21) obtained by pyrosequencing consisting of $486 \mathrm{Mb}$ with an average read length of $397 \mathrm{bp}$ and compared it with other metagenomic datasets obtained from ponds with 19,33, and $37 \%$ total salts acquired from Santa Pola marine saltern, located in Alicante, East Spain, on the Mediterranean coast. Although the salinity in IC21 is closer to the pond with 19\% total salts from Santa Pola saltern (designated as SS19), IC21 is more similar at higher taxonomic levels to the pond with 33\% total salts from Santa Pola saltern (designated as SS33), since both are predominated by the phylum Euryarchaeota. However, there are significant differences at lower taxonomic levels where most sequences were related to the genus Halorubrum in IC21 and to Haloquadratum in SS33. Within the Bacteroidetes, the genus Psychroflexus is the most abundant in IC21 while Salinibacter dominates in SS33. Sequences related to bacteriorhodopsins and halorhodopsins correlate with the abundance of Haloquadratum in Santa Pola SS19 to SS33 and of Halorubrum in Isla Cristina IC21 dataset, respectively. Differences in composition might be attributed to local ecological conditions since IC21 showed a decrease in the number of sequences related to the synthesis of compatible solutes and in the utilization of phosphonate.

Keywords: metagenomics, haloarchaea, halophilic bacteria, saltern, prokaryotic diversity

\section{INTRODUCTION}

Hypersaline habitats are characterized by high salt concentrations, in addition to other features, such as high or low temperatures, high $\mathrm{pH}$, and/or low oxygen concentrations (Javor, 1989; Rodríguez-Valera, 1993). Hypersaline environments are often aquatic systems (thalassohaline, of marine origin, or athalassohaline, formed by dissolution of mineral salt deposits of continental origin) or saline soils (Walsh et al., 2005; Ventosa, 2006; Ventosa et al., 2008), but they are also represented by salt deposits, some desert plants, oilfield brines and a variety of salted foods, from seasoned fish or meat to fermented foods as well as animal hides (Grant et al., 1998; Ventosa, 2006). The best studied hypersaline habitats are aquatic hypersaline systems, such as salt lakes and salterns.

Salterns are excellent models for studying the ecology and diversity of microorganisms, given that they are composed by a series of ponds with widely different salinities that concentrate salt from seawater to the point of saturation and precipitation. Most saltern studies have been performed on the saturated brine crystallizer ponds (Antón et al., 1999, 2000; Benlloch et al., 2001; Pašić et al., 2005; Pasić et al., 2007; Legault et al., 2006; Oh et al., 2010). Some comparative reports performed on crystallizers ponds, as Pasić et al. (2007), compared haloarchaeal communities from two Adriatic solar salterns, showing differences in the microbiota and that climate could play a role in the microbial community structure. Oh et al. (2010) examinated the diversity of Haloquadratum and other haloarchaea in three coastal, but geographically distant saltern crystallizer ponds in Australia. The great majority of the 16S rRNA gene sequences recovered from these crystallizers were related to $H$. walsbyi and diverged by less than $2 \%$ from each other, and from the type strain of this genus (strain C23). However, our knowledge about intermediate salinity ponds is limited. Benlloch et al. (2002) analyzed 16S rRNA sequences by DGGE of three salt ponds ( 8 , 22 , and $32 \%$ total salts, respectively) from Santa Pola saltern in Eastern Spain. Most bacterial sequences in the $8 \%$ salt pond were related to organisms of marine origin belonging to representatives of the classes Alpha-, Beta-, Gamma-, and EpsilonProteobacteria, and the phyla Bacteroidetes, Actinobacteria, and Cyanobacteria. In the $22 \%$ salt pond were found Alpha- and Gamma-Proteobacteria, Cyanobacteria, and Bacteroidetes, and most of them were related to specialized halophiles. From the $32 \%$ salt pond, the only Bacteria found were sequences that clustered with Salinibacter ruber, an extremely halophilic Bacteroidetes. And in those three different salinity ponds, most of the clones were related to cultured strains of the archaeal 
class Halobacteria. A metagenomic study of an intermediate salinity pond from Santa Pola saltern (SS19), revealed a low presence of bacterial species of Halomonas, Chromohalobacter, or Salinivibrio (Ghai et al., 2011), which are commonly isolated from those habitats (Arahal et al., 2001; Arenas et al., 2009) but abundant metagenomic reads affiliated to Haloquadratum walsbyi and Salinibacter ruber were also found. A novel representative of nanohaloarchaeota ("Candidatus Haloredivivus") which was also found to be abundant, and its genome was partially assembled. The most abundant bacterium found in this $19 \%$ salt pond appeared to be a gammaproteobacterium closely related to Alkalilimnicola and Nitrococcus. This microbe has been recently cultured and its genome sequenced (Leon et al., 2013; López-Pérez et al., 2013). Besides, Ghai et al. (2011) found a large number of sequences related to presumably non-halophilic bacterial genera and, a group of low $\mathrm{G}+\mathrm{C}$ Actinobacteria typical to freshwater habitats. A recent metagenomic study on a pond with 13\% salts of Santa Pola saltern showed a large microbial diversity representing seven major higher taxa: Euryarchaeota, Gammaproteobacteria, Alphaproteobacteria, Actinobacteria, Bacteroidetes, Verrucomicrobia, and Betaproteobacteria (Fernández et al., 2014a). Community analysis of an intermediate salinity pond ( $18 \%$ total salts) from a saltern in Guerrero Negro, Mexico, demonstrated that the archaeal community was dominated by a single uncultured 16S rRNA phylotype with 99\% similarity to sequences recovered from a Tunisian saltern and the most abundant bacterial sequences were 99\% similar to an uncultured gammaproteobacterial clone from the Salton Sea (Dillon et al., 2013). Boujelben et al. (2012) explored the prokaryotic community in several ponds from Sfax saltern in Tunisia. They showed that some phylotypes, such as those related to Haloquadratum or representatives of Bacteroidetes, displayed a strong dependence of salinity and/or magnesium concentrations and that temperature was a strong factor structuring the prokaryotic community in the pond with $20 \%$ salinity, but not in the crystallizer pond, due to the seasonal changes. However, a survey about six salt lakes in Inner Mongolia, China, and a salt lake in Argentina showed that archaeal biogeography was influenced by $\mathrm{Na}^{+}, \mathrm{CO}_{3}^{2-}, \mathrm{HCO}^{3-}, \mathrm{pH}$ and temperature, and bacterial biogeography was influenced by $\mathrm{Na}^{+}, \mathrm{Mg}^{2+}, \mathrm{HCO}^{3-}$, and $\mathrm{pH}$ as well as geographic distance (Pagaling et al., 2009; Grant et al., 2011).
Therefore, in order to learn more about the community structure of intermediate salinity ponds, we explored the phylogenetic and taxonomic differences as well as metabolic profiles of two geographically distant habitats from Spain: the Isla Cristina saltern that gets its water from the Atlantic Ocean and the Santa Pola saltern on the Mediterranean Sea.

\section{MATERIALS AND METHODS}

\section{SAMPLE COLLECTION, DNA EXTRACTION, AND SEQUENCING}

The metagenomic datasets analyzed in this study are derived from different saline systems: one dataset was obtained from a pond at the Isla Cristina saltern located on the Atlantic Ocean, in southwestern Spain with a salinity of $21 \%$ (Fernández et al., 2014b); four datasets were from the Santa Pola saltern located in eastern Spain on the Mediterranean Sea, of which three were from concentrator ponds (SS13, SS19, and SS33) and one from a crystallizer pond (SS37) with salt concentrations of 13, 19, 33, and 37\%, respectively (Ghai et al., 2011; Fernández et al., 2013, 2014a); and two marine datasets, deep chlorophyll maximum from Mediterranean Sea (DCM3) and Mar Menor coastal lagoon (MM5) with salinities of 3.8 and 5\%, respectively (Ghai et al., 2010, 2012). All databases were obtained using the same DNA extraction method and the samples were sequenced by pyrosequencing 454 (Martín-Cuadrado et al., 2007; Ghai et al., 2011). The accession numbers for the deposited databases are shown in Table 1.

\section{COMPARATIVE ANALYSIS OF METAGENOMIC READS}

To estimate cumulative nucleotide differences between metagenomic datasets, we carried out BLASTN searches of the complete set of sequences from every dataset vs. all the others. Bitscores of the top high-scoring segment pairs (HSPs) from every sequence from one set vs. another were summed to yield a cumulative pairwise bitscore value (CPBV) that was normalized and used to construct a distance matrix. CPBVs were normalized by dividing each one by the cumulative bistscore value derived from the BLASTN of one dataset vs. itself. The distance matrix was analyzed using the Phylip package (Felsenstein, 1989) to obtain a neighbor-joining tree.

$\mathrm{G}+\mathrm{C}$ contents were computed using the program geecee in the EMBOSS package (Rice et al., 2000) and the amino acid frequency was calculated from a perl script. The metagenomic reads were

Table 1 | Features of the different datasets from saline habitats used in this study.

\begin{tabular}{|c|c|c|c|c|c|c|c|c|}
\hline Datasets & $\begin{array}{l}\text { Salinity } \\
(\%)\end{array}$ & $\begin{array}{l}\text { Temperature } \\
\left({ }^{\circ} \mathrm{C}\right)\end{array}$ & $\mathrm{pH}$ & $\begin{array}{l}\text { Number of } \\
\text { reads }\end{array}$ & $\begin{array}{l}\text { Dataset } \\
\text { size (Mb) }\end{array}$ & $\begin{array}{l}\text { Average read } \\
\text { length (bp) }\end{array}$ & $\begin{array}{l}\text { Accession } \\
\text { number/source }\end{array}$ & References \\
\hline $\begin{array}{l}\text { Deep Chlorophyll } \\
\text { Maximum (DCM3) }\end{array}$ & 3.8 & 15.9 & 8.1 & $1,204,321$ & 312 & 259 & SRP002017 & Ghai et al., 2010 \\
\hline $\begin{array}{l}\text { Mar Menor Coastal } \\
\text { Lagoon (MM5) }\end{array}$ & 5 & 19 & 8.4 & 730,997 & 243 & 335 & http://camera.calit2.net & Ghai et al., 2012 \\
\hline Santa Pola Saltern (SS13) & 13 & 29 & 8.0 & $1,443,593$ & 441 & 305 & SRP028290 & Fernández et al., 2013, 2014a \\
\hline Santa Pola Saltern (SS19) & 19 & 30 & 8.0 & $1,315,302$ & 475 & 361 & SRP007685 & Ghai et al., 2011 \\
\hline Santa Pola Saltern (SS33) & 33 & 30 & 7.0 & 842,872 & 309 & 367 & SRP028290 & Fernández et al., 2013 \\
\hline Santa Pola Saltern (SS37) & 37 & 41 & 7.1 & 760,740 & 309 & 417 & SRP007685 & Ghai et al., 2011 \\
\hline Isla Cristina Saltern (IC21) & 21 & 25 & 7.5 & $1,223,923$ & 486 & 397 & SRP029970 & Fernández et al., 2014b \\
\hline
\end{tabular}


annotated using UniProtKB database released in December 2013 (UniProt Consortium, 2014) through BLASTX search with a cutoff $e$-value of $1 \mathrm{e}-5$.

$16 \mathrm{~S}$ ribosomal RNA genes were identified by comparing the datasets against the RDP database version 11.1 (Cole et al., 2014). All reads that matched a $16 \mathrm{~S}$ rRNA sequence with an alignment length of more than $100 \mathrm{bp}$ and an $e$-value lower than 1e-5 against the database were extracted. The best hit that was not described as unknown or unidentified was considered a reasonable closest attempt for classifying the $16 \mathrm{~S}$ rRNA sequences. Sequences were assigned to a specific genus if they shared $\geq 95 \% 16 \mathrm{~S}$ rRNA sequence identity with a known representative.

\section{METAGENOMIC READS ASSEMBLY}

Assembly of the metagenomic reads with greater than $100 \mathrm{bp}$ was performed using stringent criteria requiring an overlap of at least $80 \mathrm{bp}, 99 \%$ identity and at most a single gap in the alignment (using Geneious Pro 5.4). Next, assembled contigs that were less than $3 \mathrm{~kb}$ in length, and those with less than three predicted genes were discarded for further analysis. We retained only those contigs that provided consistent query hits to only single high level taxa (e.g., Alphaproteobacteria, Euryarchaeota, Bacteroidetes, Actinobacteria). To test if the assembly strategy produced authentic contigs from known organisms, we manually identified all contigs that belonged to $H$. walsbyi, one of the abundant organism in the datasets. The criterion was that all genes from a putative $H$. walsbyi contig must return best hits from that genome.

Tetranucleotide frequencies of the assembled contigs were computed using the wordfreq program in the EMBOSS package (Rice et al., 2000), and principal component analysis (PCA) was performed using the R package FactoMineR (Lê et al., 2008).

\section{CONSTRUCTION OF PHYLOGENETIC TREES}

Maximum likelihood reference trees were constructed using RaxML as implemented in ARB software package (Ludwig et al., 2004) using reference 16S rRNA gene sequences with near full length (>1300 nt) from cultured isolates. Later, partial $16 \mathrm{~S}$ rRNA gene assembled metagenomic sequences and closely related environmental uncultured 16S rRNA gene sequences were inserted into reference trees without altering tree topology using maximum parsimony criterion and a $50 \%$ base frequency filter. Bootstrap values greater than $50 \%$ are indicated above nodes and the scale bar represents 10 base substitutions per $100 \mathrm{nt}$ positions. The 16S rRNA gene sequences retrieved in this study were deposited in Genbank under accession numbers KJ546108KJ546118, KJ588879-KJ588888, KJ588892-KJ588898 (archaeal) and KJ588890-KJ588891, KJ588899-KJ588905 (bacterial).

\section{RESULTS AND DISCUSSION FEATURES OF DATASETS}

In this study several metagenomic datasets were examined (Table 1). The thalassosaline waters of the salterns in Santa Pola and Isla Cristina have a marine origin but they have a different source: the Mediterranean Sea and the Atlantic Ocean, respectively. Besides their high salt concentrations, these environments are subject to strong solar irradiation (Rodríguez-Valera et al.,
1985; Rodríguez-Valera, 1988). In order to determine how a gradient of salinity influences microbial communities, we compared metagenomes datasets of Santa Pola and Isla Cristina salterns and DCM3 and MM5 from marine sites (Figure 1). We expected marine derived datasets to form their own branch separate from the saltern datasets and that IC21 should be closer to SS19 than SS33, because salinity has been identified as the main factor determining the distribution of prokaryotic organisms in aquatic systems (Lozupone and Knight, 2007; Schapira et al., 2009). As expected, the phylogenetic tree showed that marine datasets, DCM3 and MM5 clearly differed from the saltern datasets, sharing a low number of sequences with them, and the saltern datasets were more similar to each other, making it possible to recognize the impact of a salinity gradient. Unexpectedly however, the community from IC21 was closer in structure to both the datasets, SS19 and SS33, although the salt concentration in IC21 was nearer to the dataset SS19, suggesting community composition is affected by local environmental characteristics. Thus, we focused this study on the intermediate salinity ponds and analyzed the datasets qualitatively and quantitatively to elucidate potential causes that might produce the observed differences.

A well-known adaptive feature for living at high salt concentration is the enrichment of acidic amino acids in proteins allowing them to properly function at high cytoplasmic salinities (Soppa, 2006). Therefore, we analyzed the isoelectric point and amino acids frequencies of proteins, which would reflect this adaptation. Surprisingly, IC21 proteins were more similar to those in SS33 than to SS19 (Figure 2). The dataset IC21 showed an increase in acidic amino acids compared to SS19 that therefore indicates a greater presence of microorganisms using the "salt-in" strategy to osmotically balance their cytoplasm with their environment (Oren, 2008, 2013).

High $\mathrm{G}+\mathrm{C}$ content is often associated with the presence of haloarchaea, except for the well-known exception Haloquadratum and is a useful predictor of community composition. Analysis showed that the G+C content of IC21 (Figure 3) had a bimodal distribution more similar to SS19 than to SS33, and the predominant peak in both is at $\sim 65 \%$. This peak is consistent

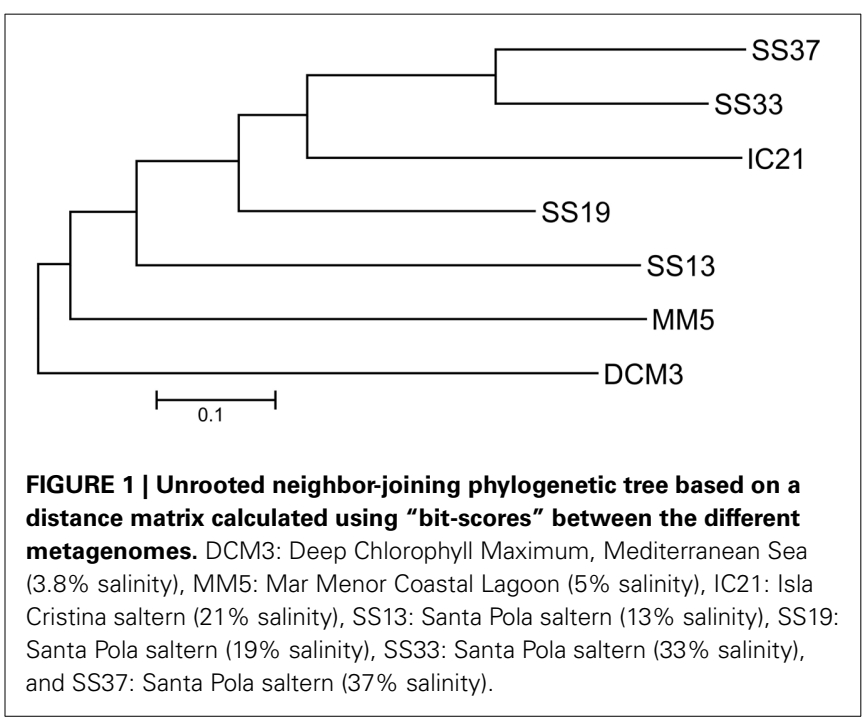



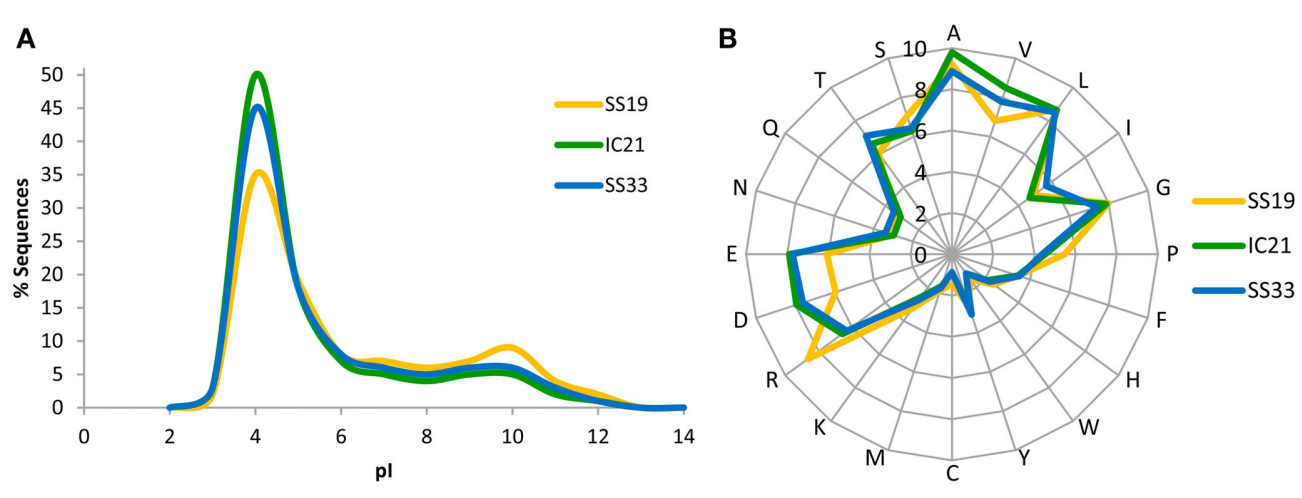

FIGURE 2 | Isoelectric point (pl) profiles (A) and amino acid frequency (B) of the predicted proteins in the metagenomic datasets SS19, IC21, and SS33. The $\mathrm{pl}$ was computed for each translated read and is shown as a percentage of the dataset in intervals of bin width 2 .

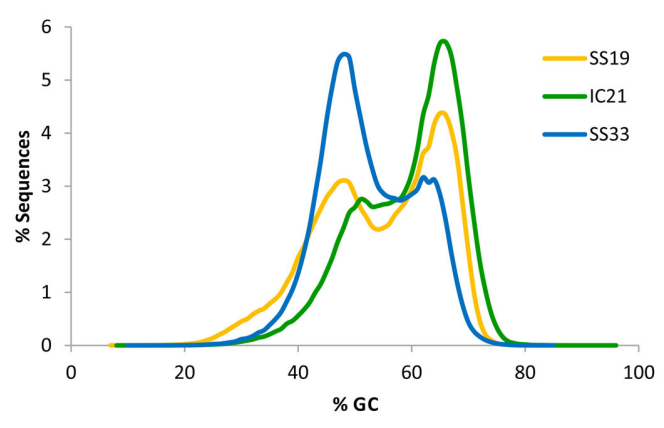

FIGURE 3 | Comparison of $\mathbf{G}+\mathbf{C} \%$ of sequences from metagenomic datasets SS19, IC21, and SS33. G+C\% was computed for each read and the percentage of the dataset in intervals of bin width 10 is shown.

with the high $\mathrm{G}+\mathrm{C}$ content associated with most halophilic archaea and bacteria described so far (Paul et al., 2008). Ponds from Santa Pola saltern (SS19 and SS33) exhibited a low G+C peak at $47.9 \%$, which has previously been observed to increase at higher salinities (Ghai et al., 2011). This low G+C peak comes from Haloquadratum walsbyi (Bolhuis et al., 2006) and perhaps from the newly reported nanohaloarchaea (Ghai et al., 2011). In IC21 the low G+C peak is shifted to a value slightly higher than that observed in metagenomic datasets from Santa Pola ponds, SS19 and SS33, around 51-52\%. This low G+C peak might correspond to genera containing representatives of halophilic bacterial genera such as Halomonas, Salimicrobium, or Salinicoccus. These genera have DNA G+C contents in the range of $52.0-74.3,44.9-51.5$, and $46-51.2 \%$, respectively (de la Haba et al., 2011). Another possibility is that it corresponds to halophilic or halotolerant microorganism not yet described, or to AT-rich regions in haloarchaeal genomes (Ram Mohan et al., 2014) In members of the order Halobacteriales a "minor component" of the DNA (10-30\% of the total DNA) with a G+C range of 51-59 mol\% has been reported (Grant et al., 2001).

\section{PROKARYOTIC COMMUNITY STRUCTURE}

The taxonomic diversity was analyzed carrying out a search of the metagenomic sequences related to the $16 \mathrm{~S}$ rRNA gene using the RDP database and selecting those sequences with a minimum length of $100 \mathrm{bp}$ and an identity over $80 \%$ for higher taxonomic levels (Figure 4) and 95\% for the genus level (Table 2).

In Figure 4 it is observed that the bacterial community decreases sharply in IC21 compared to SS19, shifting to a largely archaeal community. Also identified are members of 14 higher taxa in SS19 but interestingly we found only six in IC21 and five in SS33. The phyla Euryarchaeota and Bacteroidetes and the class Gammaproteobacteria are shared by the three datasets, but there are numerically more sequences related to the phylum Euryarchaeota with increasing salinity and a concurrent decrease for the other two. Further, these data show that the phyla biodiversity in IC21 is more similar to SS33 than to SS19. Ghai et al. (2011) analyzed the changes of the biodiversity along a salinity gradient in two metagenomic datasets (with 19 and 37\% salts) from Santa Pola saltern. The biodiversity detected in the crystallizer pond (SS37) is quite similar to that determined for SS33, due to their extreme salinities; however in the crystallizer pond only two phyla were found, corresponding to Euryarchaeota and Bacteroidetes.

The simplification of the prokaryotic community at higher salinities is also seen at the genus level: the number of sequences related to different genera decreases from 69 in SS19 to 28 and 16 in IC21 and SS33, respectively. The most abundant sequences in all three datasets are related to the archaeal genera Halorubrum, Haloquadratum, and Natronomonas, recruiting more Halorubrum sequences in SS19 and IC21 (12.5 and 65.8\%, respectively) and Haloquadratum in SS33 (29.5\%) (Table 2). The genus Salinibacter (belonging to the Bacteroidetes) is the next taxon highly represented in Santa Pola datasets with 6.4 and $4.7 \%$ of the sequences in SS19 and SS33, respectively. However, in IC21 the second predominant genus is Psychroflexus, also a member of the phylum Bacteroidetes, at $4.6 \%$ of the sequences. The six species comprising the genus Psychroflexus (P. gondwanense, P. halocasei, P. salinarum, $P$. sediminis, $P$. torquis, and $P$. tropicus) have been characterized as slightly or moderately halophilic bacteria and most of them have been isolated from saline environments (Bowman et al., 1998; Donachie et al., 2004; Chen et al., 2009; Yoon et al., 2009; Seiler et al., 2012). With respect to genera of the class Gammaproteobacteria, in SS19 and IC21, Spiribacter is identified as one of the most abundant. In spite of the strain "Spiribacter 

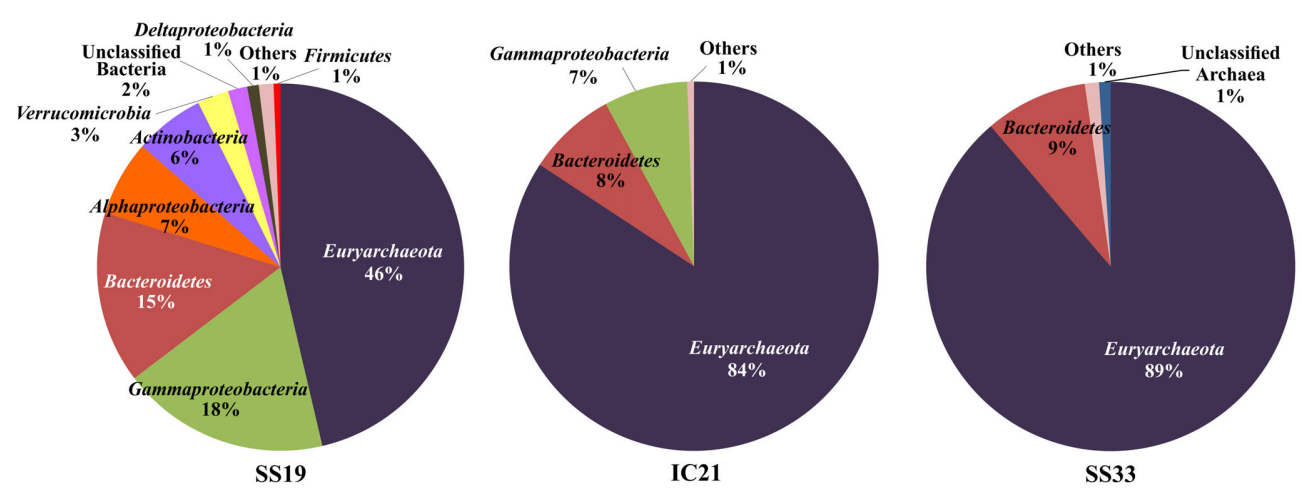

FIGURE 4 | Representation of high taxonomic levels affiliated to metagenomic rRNA reads. Assigned sequences have an identity over $80 \%$ and a minimum length of $100 \mathrm{bp}$.

Table 2 | Microbial diversity at genus level in the metagenomic datasets SS19, IC21, and SS33.

\begin{tabular}{|c|c|c|c|c|c|c|}
\hline \multirow[t]{2}{*}{ Sample } & \multicolumn{2}{|l|}{ SS19 } & \multicolumn{2}{|l|}{ IC21 } & \multicolumn{2}{|l|}{ SS33 } \\
\hline & Halorubrum & $12.5 \%$ & Halorubrum & $65.8 \%$ & Haloquadratum & $29.5 \%$ \\
\hline & Haloquadratum & $7.9 \%$ & Psychroflexus & $4.6 \%$ & Halorubrum & $23.1 \%$ \\
\hline & Natronomonas & $5.6 \%$ & Haloquadratum & $1.9 \%$ & Salinibacter & $4.7 \%$ \\
\hline & "Spiribacter" & $4.4 \%$ & "Spiribacter" & $1.1 \%$ & Haloplanus & $3.4 \%$ \\
\hline & Arhodomonas & $1.8 \%$ & & & & \\
\hline & Aquiluna* & $1.5 \%$ & & & & \\
\hline & Oceanicola & $1.1 \%$ & & & & \\
\hline Total number of sequences & & 1477 & & 1538 & & 888 \\
\hline Total number of genera & & 69 & & 28 & & 16 \\
\hline
\end{tabular}

Assigned sequences have a $16 \mathrm{~S}$ rRNA identity over $95 \%$ and a minimum length of $100 \mathrm{bp}$. Only those genera with more than $1 \%$ of assigned sequences are shown. SS19: Santa Pola saltern (19\% salinity), IC21: Isla Cristina saltern (21\% salinity), and SS33: Santa Pola saltern (33\% salinity).

${ }^{*}$ Candidatus.

salinus" M19-40 being isolated from Isla Cristina saltern (Leon et al., 2013; López-Pérez et al., 2013), it was more abundant in SS19 compared to IC21 ( $4.4 \%$ vs. $1.1 \%$, respectively). In fact, Ghai et al. (2011) reported a great abundance of sequences belonging to Gammaproteobacteria related to the genus Alkalilimnicola, which later was assigned to "S. salinus" M19-40 (López-Pérez et al., 2013). Although at the phylum or class level IC21 is more similar to SS33 at the genus level the Isla Cristina dataset differs in biodiversity and abundance from both Santa Pola datasets, demonstrating an overrepresentation of the genus Halorubrum and decrease in the sequences $(0.4 \%)$ related to Salinibacter in IC21. Ghai et al. (2011) observed that in Santa Pola datasets (SS19 and SS37) the species Salinibacter ruber appeared as an abundant microorganism, but in IC21 it is much lower.

Traditional culture methods carried out in Santa Pola saltern determined that in intermediate salinity ponds there were a variety of moderately halophilic microorganisms (Rodríguez-Valera et al., 1985). Subsequent studies performed by molecular techniques indicated that these prokaryotic representatives belong in the groups Gammaproteobacteria, Bacteroidetes, and Halobacteriaceae and in a pond with $22 \%$ total salts $16 \mathrm{~S}$ rDNA sequences were related to the genera Psychroflexus, Halorubrum, and Natronomonas (Benlloch et al., 2002); similar results were obtained in the dataset IC21. In a recent study of a pond from the Exportadora de Sal (ESSA) evaporative saltern in Guerrero Negro (Mexico) with 18\% total salts a Halorubrum-like sequence nearly identical ( $>99.5 \%$ similar) to environmental sequences from the Santa Pola saltern as well as sequences $97 \%$ similar to "S. salinus" were reported (Dillon et al., 2013). Recently, Podell et al. (2013) found that the microbial composition from Lake Tyrrell (Australia) was correlated with concentrations of potassium, magnesium, and sulfate, but not sodium, chloride, or calcium ions. Sequences related to Haloquadratum were positively correlated with potassium, magnesium, and sulfate ions while sequences related to Halorubrum, Haloarcula, Halonotius, Halobaculum, and Salinibacter were negatively correlated with them. In addition, $H$. walsbyi shows a higher tolerance to $\mathrm{Mg}^{2+}$ than other halophilic archaea (Bolhuis 
et al., 2004; Burns et al., 2004). The differences found among Isla Cristina and Santa Pola datasets, mainly due to the dominance of sequences related to Halorubrum in IC21 and to Haloquadratum in SS19 and SS33, might be explained by the difference in the ionic composition of both samples as previously reported in other hypersaline habitats (Pagaling et al., 2009; Grant et al., 2011; Boujelben et al., 2012; Podell et al., 2013).

\section{CONTIGS OF CONCENTRATOR PONDS}

It is expected that contigs assembled from metagenomic reads will yield genomic fragments derived from the most abundant organisms in the sample (Ghai et al., 2011). Assembled contigs from the metagenomic datasets SS19, IC21, and SS33 were assembled and tested against the genome of an abundant organism in the datasets, H. walsbyi. In SS19, a total of 84 contigs larger than $5 \mathrm{~kb}$ were assembled, 69 could be assigned to the phylum Euryarchaeota and 15 to the class Gammaproteobacteria (Ghai et al., 2011). In IC21 710 contigs with at least $5 \mathrm{~kb}$ were obtained; 618 were assigned to the phylum Euryarchaeota, 85 contigs to the class Gammaproteobacteria and 7 contigs to viruses. With respect to SS33 a total of 248 contigs were assembled, 247 were assigned to Euryarchaeota and 1 to the phylum Bacteroidetes. A PCA on the normalized tetranucleotide frequencies of the contigs belonging to the most abundant groups was carried out (Figure 5). The contigs from SS19 and IC21 had consistent hits to taxa within the Euryarchaeota and Gammaproteobacteria and from SS33 the majority were Euryarchaeota. Contigs related to the phylum Euryarchaeota are grouped in two different clusters with low $\mathrm{G}+\mathrm{C}$ content, one of them closely related to $H$. walsbyi, comprising 30 and 222 contigs of SS19 and SS33, respectively, and the second cluster related to the nanohaloarchaeon "Candidatus Haloredivivus" forming 11 contigs of the SS19. Additionally, we observed a third cluster including Euryarchaeota of high $\mathrm{G}+\mathrm{C}$ content, comprising contigs from the three datasets that were related to genomes of extremely halophilic archaea. On the other hand, many contigs related to Euryarchaeota from the three datasets did not cluster with contigs related to $H$. waslbyi nor Euryarchaeota of high $\mathrm{G}+\mathrm{C}$ content. Their $\mathrm{G}+\mathrm{C}$ content values are between the extremely halophilic archaeal reference genomes and $H$. walsbyi; possibly these contigs belong to unknown hyperhalophilic archaea. A fourth cluster of Gammaproteobacteria contigs from SS19 (13 contigs) and IC21 (71 contigs) was closely related to the genome of "Spiribacter salinus" M19-40 (LópezPérez et al., 2013).

Because of the unique $\mathrm{G}+\mathrm{C}$ content, the contigs with a 51$52 \% \mathrm{G}+\mathrm{C}$ in IC21 were further examined (Figure 3). Contigs associated with Gammaproteobacteria and viruses did not have this $\mathrm{G}+\mathrm{C}$ content, ruling them out as contributors. However, among the nine contigs related to Euryarchaeota, three could clearly be assigned to Halorubrum and also had similar G+C
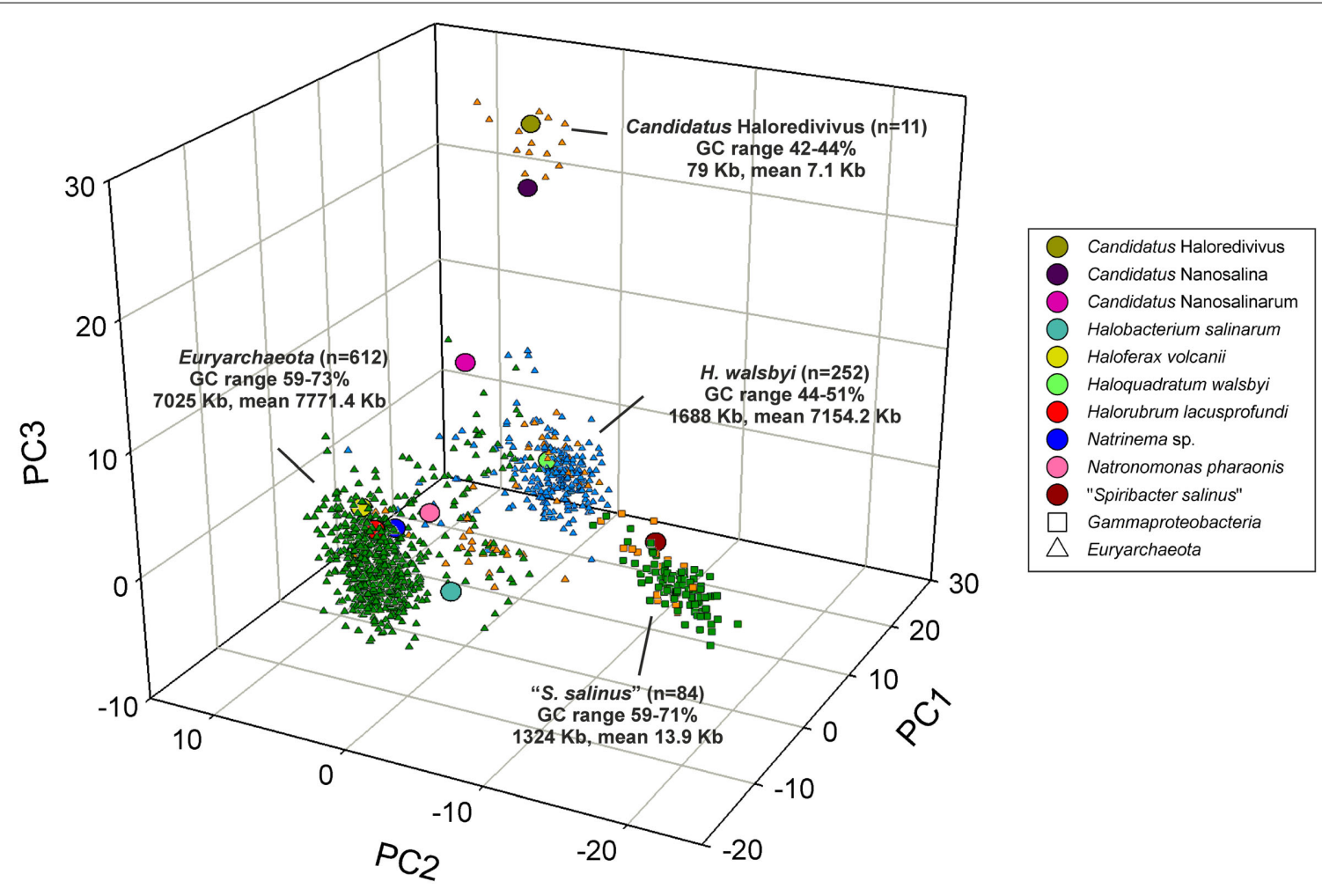

FIGURE 5 | Principal component analysis of tetranucleotide frequencies of assembled contigs from SS19, IC21, and SS33 datasets. Reference genomes are shown as larger circles. The following types of contigs are shown: orange: SS19 contigs, Green:
IC21 contigs, Blue: SS33 contigs, Square: Gammaproteobacterial contigs, Triangle: Euryarchaeota contigs. The total number of contigs for each cluster, the total length, mean length, and $\mathrm{G}+\mathrm{C} \%$ range is also indicated. 
content. These contigs mainly contain genes for ABC transporters, metallophosphoesterase, multi-sensor signal transduction histidine kinase, and hypothetical proteins.

Further taxonomic analysis was performed on 16S rRNA genes from assembled metagenomic reads longer than $500 \mathrm{bp}$. We found eight $16 \mathrm{~S}$ rRNA sequences from each of the datasets SS33 and IC21, and 11 sequences from the dataset SS19 that were analyzed using BLAST (Figure 6). One assembled sequence from each of the datasets grouped within the Haloquadratum cluster together with uncultured archaeal sequences from Lake Tyrrell, VIC, Australia (with 29\% salinity). The 16S rRNA sequences from SS19, IC21, and SS33 had high similarity with $H$. walsbyi HBSQ001 of 100, 99.9, and 98.9\%, respectively. Only one sequence from SS33 was found within the Haloplanus cluster with a similarity of $98.0 \%$ to Haloplanus natans and $97.8 \%$ to an uncultured archaeon sequence of a saline soil from Jiangsu (China). Three sequences from IC21 and one sequence from SS19 were included into the Halorubrum cluster. One sequence from IC21 shared with Hrr. chaoviator a similarity of $99.2 \%$, another sequence from IC21 had a similarity of 99.4 and $99.3 \%$ with two different sequences of uncultured archaea from Aran-Bidgol salt lake (salinity over 30\%) and other sequence from IC21 shared a similarity of $99.5 \%$ with a sequence from SS19 and with $\mathrm{Hrr}$. orientale. Within the Halohasta cluster one sequence from IC21 had a similarity of $98.8 \%$ to Halohasta litorea. The "Candidatus Haloredivivus" cluster was represented by one sequence from SS19. The rest of the contigs could not be classified into knownarchaeal genera. The assembled 16S rRNA sequences from the three datasets showing the presence of potential microorganisms related to Haloquadratum (although in IC21 representatives of this genus do not appear to be very abundant) and uncultured archaea in clusters 3 and 5. In IC21 the assembled sequences show a high abundance of members of the genus Halorubrum. A pattern regarding the community composition among the datasets studied appears to be absent, but we do find evidence that some sequences from different hypersaline environments are related to them. This suggests unknown environmental parameters affect community composition, and/or perhaps random dispersal and horizontal gene transfer of key adaptive genes play a role. For instance, Parnell et al. (2010) demonstrated that genes providing adaptation to their niche, rather than the taxa living there, structured halophilic communities in the Great Salt Lake.

Additionally, we found $16 \mathrm{~S}$ rRNA assembled metagenomic reads longer than 500 bp related to the phylum Bacteroidetes: four from SS19, two from IC21 and one from SS33 (Figure 7). We used BLAST to search in the $\mathrm{nr} / \mathrm{nt}$ database the sequences showing a higher similarity to the $16 \mathrm{~S}$ rRNA assembled sequences of Bacteroidetes. A first cluster related to Psychroflexus was detected including one sequence from IC21. This sequence was similar to an uncultured bacterium from a Tibetan hypersaline lake (96.4\%) and Psychroflexus sediminis (95.7\%). One sequence from SS19 was within the Salinibacter cluster, showing a $92.1 \%$ similarity to Salinibacter ruber. The rest of the sequences from SS19, IC21, and SS33 could not be classified into any cluster containing cultured microorganisms. The $16 \mathrm{~S}$ rRNA assembled metagenomic reads of Bacteroidetes show that in SS19 this taxon is more abundant than
IC21 and SS33, with predominance of sequences related to uncultured bacteria, while in the dataset IC21 Psychroflexus was the genus that recruited more $16 \mathrm{~S}$ rRNA sequences (Table 2). Neither of the 16S rRNA assembled sequences related to Bacteroidetes in IC21 are related to any of the assembled sequences of SS19 and SS33.

Although at high taxonomic levels IC21 is more similar to SS33 than SS19, the fact is that IC21 and SS33 are different with respect to the genera and their abundance observed as well as to the presence of different uncultured taxa. In saline and alkaline lakes in Iran a similar composition of microbial communities but differing in community structure has been reported (Makhdoumi-Kakhki et al., 2012).

\section{METABOLIC PROFILE}

To analyze the metabolic diversity in the dataset IC21, we determined the relative abundance of individual genes involved in metabolic pathways of the datasets SS19, SS33, and IC21 (Supplementary Table 1) by searching predicted metagenomic proteins with the UniprotKB database (UniProt Consortium, 2014) using BLASTX (Camacho et al., 2008).

Metabolism based on energy from light was queried in our data sets. Because our screening protocol removed eukaryotic microorganisms, only prokaryotic microorganisms were considered in this analysis. The photosynthetic reaction centers, $p s b A$ and $p s b D$ genes, were not detected in the three datasets analyzed and therefore we can conclude that photosynthesis by prokaryotes was absent in these datasets. Instead, genes coding different types of rhodopsins were found suggesting that light is widely used as an energy source in these conditions, just not for carbon fixation. It was observed that bacteriorhodopsins and halorhodopsins increased in frequency at higher salinities. Bacteriorhodopsins associated with Haloquadratum were in a greater proportion in Santa Pola saltern datasets while in IC21 they were associated with Halobacterium and Halorubrum. Halorhodopsins related to Halobacterium were found in high proportion in all datasets but the number of sequences belonging to Haloquadratum is greater in Santa Pola saltern and those from Halorubrum are higher in IC21. Sequences related to bacteriorhodopsins and halorhodopsins show clearly the abundance of Haloquadratum in Santa Pola SS19 and SS37 datasets and Halorubrum in Isla Cristina IC21 dataset.

Microorganisms under osmotic stress conditions use different survival strategies. Most bacteria maintain cell integrity through accumulation of compatible solutes ("salt-out" strategy). Sequences related to genes of compatible solutes were mainly glutamate synthase, betaine transporters, glycerol kinase, and glycerol-3-phosphate dehydrogenase, and at lower frequencies were glycerol and glutamate transporters. In IC21 lower number of sequences related to choline dehydrogenase, glutamate synthase, and trehalose synthase were observed compared to Santa Pola datasets, suggesting a higher synthesis of these compatible solutes in Santa Pola saltern. The proportion of sequences related to compatible solutes decreased with the salinity except for glycerol degradation (glycerol kinase, glycerol-3-phosphate dehydrogenase, and dihydroxyacetone kinase), increasing the number of sequences in the dataset SS33 compared to SS19 


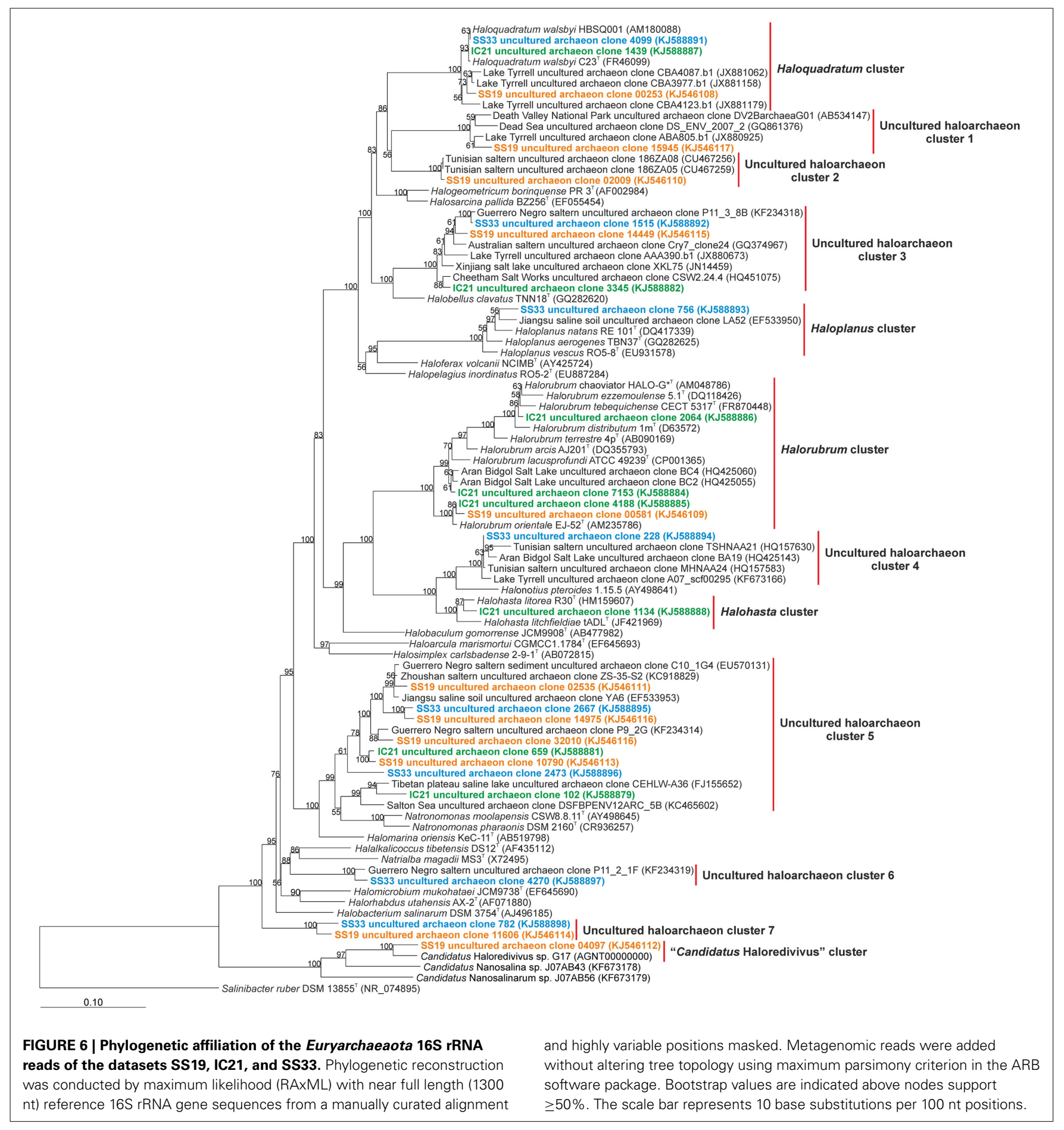

(number of sequences relative to the total number of metagenomic sequences). This result could indicate a higher presence of the algae Dunaliella or a higher primary production of glycerol, which is the predominant compatible solute in Dunaliella or alternatively, the oxidation of glycerol to dihydroxyacetone, that has been studied in the species Salinibacter ruber and is used as a growth substrate by $H$. walsbyi and Haloferax volcanii (Elevi Bardavid and Oren, 2008; Ouellette et al., 2013). Therefore, glycerol and probably dihydroxyacetone are considered as the main carbon source and energy for the heterotrophic community in salterns (Borowitzka and Brown, 1974; Borowitzka et al., 1977; Ouellette et al., 2013).

With respect to the nitrogen cycle, it seemed to be simplified in the saltern datasets analyzed, with a decrease of the number of sequences involved in the reduction of nitrate to nitrite by nitrate reductase and nitrite to nitric oxide by nitrite reductase in SS33. 


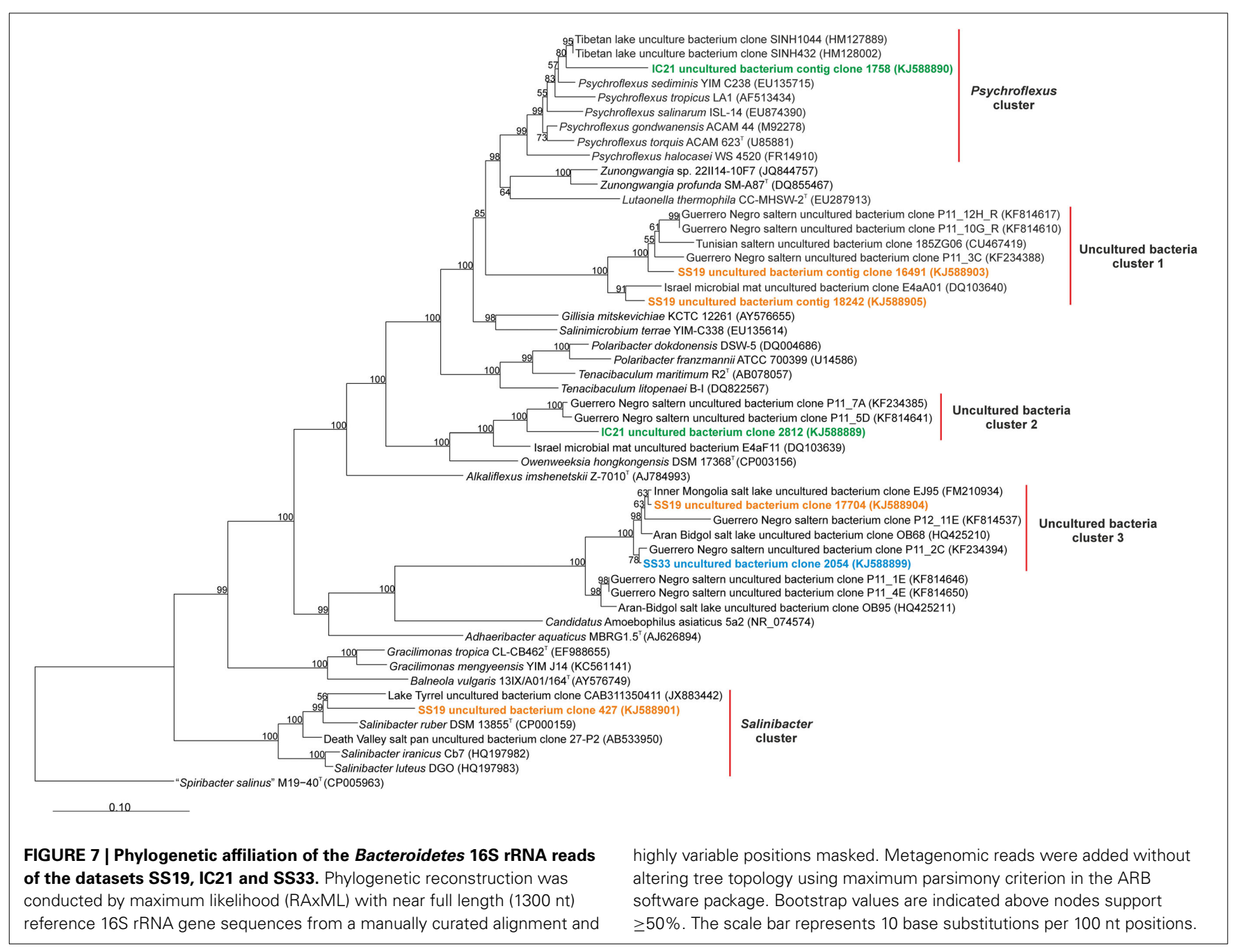

In salterns, sulfate is concentrated along the ponds until its saturation and precipitates forming calcium sulfate (gypsum) (Landry and Jaccard, 1984). Dissimilatory sulfate reduction has been reported until salt concentrations of $24 \% \mathrm{NaCl}$ (Oren, 1988). We detected sequences of genes involved in a complete dissimilatory sulfate reduction (sulfate adenylyltransferase, adenylylsulfate kinase, phosphoadenylylsulfate reductase, and sulfite reductase) in all datasets studied, except for adenylylsulfate kinase in SS33 dataset. The microbial communities of salterns are traditionally considered heterotrophic, but chemolithotrophic bacteria can also be abundant and active in extreme conditions. In particular, chemolithotrophic sulfur-oxidizing bacteria are able to adapt well to hypersaline conditions because the complete oxidation of sulfide or thiosulfate to sulfate has high energy efficiency (Oren, 1999). In spite of this, we only found some sequences of sulfide dehydrogenase that oxidizes sulfide to sulfate in SS19. Therefore, an incomplete cycle of sulfate is observed in the datasets. In fact, salterns are generally considered eutrophic media and so the pressure of selection that favors organisms with biosynthetic capabilities with full paths is probably weak (Rodríguez-Valera et al., 1981). Additionally, this pathway may be carried out by phototrophic sulfur-oxidizing bacteria in anoxic sediments, as hydrogen sulfide is considered an important transporter of electrons between the aerobic and anaerobic habitats (Jørgensen, 1982).

Phosphate regulon (Pho) plays a key role in phosphate homeostasis, products are involved in the transport and use of several forms of phosphates (Torriani and Ludtke, 1985; Shinagawa et al., 1987; Wanner, 1987, 1993). In the datasets studied a scarce number of sequences related to genes included in Pho regulon, as phoR (environmental phosphate sensor) and $p h o B$ (regulon activator) were found. However, in the dataset IC21 more sequences corresponding to the negative regulator protein of Pho regulon, PhoU and less for genes involved in the utilization of phosphonate were detected compared to the datasets SS19 and SS33. In Santa Pola saltern the total phosphorus concentration increases with the salinity (Rodríguez-Valera et al., 1985). However, the brines support high $\mathrm{Mg}^{2+}$ concentrations limiting the availability of inorganic phosphate (Bolhuis et al., 2006) and induce the use of phosphonate (Fox and Mendz, 2006). A recent study suggests the utilization of DNA as a phosphate source (Chimileski et al., 2014). 
Overall, the main differences found among Isla Cristina and Santa Pola datasets at the metabolic level were a higher number of sequences related to genes involved in the synthesis of compatible solutes (such as choline dehydrogenase, glutamate synthase, and trehalose synthase) and in the utilization of phosphonate in Santa Pola datasets with respect to IC21. This is related to the microbial strategies of haloadaptation to these extreme environments by the different microbial communities present of these habitats as well as the ionic composition of the samples.

\section{CONCLUSIONS}

Santa Pola saltern was built in 1890 over an ancient freshwater lake and close to the Mediterranean Sea (Dulau, 1983). By contrast, Isla Cristina saltern was built in 1955 over wetlands at the marsh of the river Carreras in the village of Isla Cristina, closely located to food-processing industries (Moreno et al., 2009). Santa Pola saltern is subjected to climatic conditions characterized by low annual rainfall and moderate temperatures, with little fluctuation between summer and winter (Rodríguez-Valera et al., 1985). However, Isla Cristina saltern is subjected to rainfall seasons, high solar radiation, and larger temperature fluctuations between day and night (Moreno et al., 2009). Although salinity has been considered the main factor involved in the structure of microbial biodiversity in saline aquatic systems, the data from our study strongly suggests that other factors may influence the composition of hypersaline aquatic microbial communities such as geographic locations (Naor et al., 2012; Zhaxybayeva et al., 2013) and environmental characteristics. The environmental conditions in Santa Pola saltern are more stable than in Isla Cristina saltern, therefore, the prokaryotic community in Santa Pola saltern is more stable over time, and in Isla Cristina saltern the habitat might be continuously recolonizing. Therefore, the differences between these two environments might be due to stable or unstable environmental conditions. The IC21 dataset looks more similar to SS33 dataset because they are mainly composed of representatives of the phylum Euryarchaeota, but the reality is that the community structure in IC21 is different because the most abundant genus in IC21 is Halorubrum, in contrast to Haloquadratrum, which predominates in SS33 dataset. The phylum Bacteroidetes is present in all datasets, but in the Santa Pola saltern datasets the most abundant genus of this phylum is Salinibacter, while in Isla Cristina saltern dataset is the genus Psychroflexus. Additionally, in Santa Pola datasets there are a higher number of sequences related to genes involved in the synthesis of compatible solutes and in the utilization of phosphonate, indicating some differences in the functional activity. Despite the results obtained, it is not clear what is causing the variations between these salterns; a detailed physico-chemical comparative study would be required to elucidate if the microbial structure is being influence by abiotic factors or by biogeographic situation.

\section{AUTHOR CONTRIBUTIONS}

Antonio Ventosa, R. Thane Papke, Francisco Rodriguez-Valera, and Ana B. Fernández conceived the study. Ana B. Fernández and Cristina Sánchez-Porro obtained the metagenome. Ana B. Fernández, Blanca Vera-Gargallo, and Rohit Ghai performed the analysis. Ana B. Fernández, R. Thane Papke, Francisco RodriguezValera, and Antonio Ventosa wrote the manuscript. All authors read and approved the final manuscript.

\section{ACKNOWLEDGMENTS}

This work was supported by grants from the Spanish Ministry of Science and Innovation (CGL2010-19303), the National Science Foundation (award numbers DEB0919290 and DEB0830024), MICROGEN (Programa CONSOLIDER-INGENIO 2010 CDS2009-00006), NASA Astrobiology: Exobiology and Evolutionary Biology Program Element (Grant Number NNX12AD70G), the Generalitat Valenciana (DIMEGEN PROMETEO/2010/089 and ACOMP/2009/155), MaCuMBA Project 311975 of the European Commission FP7 and the Junta de Andalucía (P07-CVI-03150 and P10-CVI-6226). FEDER funds also supported this project. Ana B. Fernández was supported by a postdoctoral contract from the Junta de Andalucía and Rohit Ghai was supported by a Juan de la Cierva scholarship from the Spanish Ministry of Science and Innovation.

\section{SUPPLEMENTARY MATERIAL}

The Supplementary Material for this article can be found online at: http://www.frontiersin.org/journal/10.3389/fmicb.2014. 00196/abstract

\section{REFERENCES}

Antón, J., Llobet-Brossa, E., Rodríguez-Valera, F., and Amann, R. (1999) Fluorescence in situ hybridization analysis of the prokaryotic community inhabiting crystallizer ponds. Environ. Microbiol. 1, 517-523. doi: 10.1046/j.14622920.1999.00065.x

Antón, J., Rosselló-Mora, R., Rodríguez-Valera, F., and Amann, R. (2000). Extremely halophilic bacteria in crystallizer ponds from solar salterns. Appl. Environ. Microbiol. 66, 3052-3057. doi: 10.1128/AEM.66.7.3052-3057.2000

Arahal, D. R., García, M. T., Vargas, C., Cánovas, D., Nieto, J. J., and Ventosa, A. (2001). Chromohalobacter salexigens sp. nov., a moderately halophilic species that includes Halomonas elongata DSM 3043 and ATCC 33174. Int. J. Syst. Evol. Microbiol. 51, 1457-1462. doi: 10.1099/00207713-51-4-1457

Arenas, M., Bañón, P. I., Copa-Patiño, J. L., Sánchez-Porro, C., Ventosa, A., and Soliveri, J. (2009). Halomonas ilicicola sp. nov., a moderately halophilic bacterium isolated from a saltern. Int. J. Syst. Evol. Microbiol. 59, 578-582. doi: 10.1099/ijs.0.003509-0

Benlloch, S., Acinas, S. G., Antón, J., López-López, A., Luz, S. P., and RodríguezValera, F. (2001). Archaeal biodiversity in crystallizer ponds from a solar saltern: culture versus PCR. Microb. Ecol. 41, 12-19. doi: 10.1007/s002480000069

Benlloch, S., López-López, A., Casamayor, E. O., Ovreas, L., Goddard, V., Daee, F. L., et al. (2002). Prokaryotic genetic diversity throughout the salinity gradient of a coastal solar saltern. Environ. Microbiol. 4, 349-360. doi: 10.1046/j.14622920.2002.00306.x

Bolhuis, H., Palm, P., Wende, A., Falb, M., Rampp, M., Rodríguez-Valera, F., et al. (2006). The genome of the square archaeon Haloquadratum walsbyi: life at the limits of water activity. BMC Genomics 7:169. doi: 10.1186/1471-2164-7-169

Bolhuis, H., Poele, E. M., and Rodriguez-Valera, F. (2004). Isolation and cultivation of Walsby's square archaeon. Environ. Microbiol. 6, 1287-1291. doi: 10.1111/j.1462-2920.2004.00692.x

Borowitzka, L. J., and Brown, A. D. (1974). The salt relation of marine and halophilic species of the unicellular green alga, Dunaliella. The role of glycerol as compatible solute. Arch. Mikrobiol. 96, 37-52. doi: 10.1007/BF00590161

Borowitzka, L. J., Kessly, D. S., and Brown, A. D. (1977). The salt relations of Dunaliella. Further observations on glycerol production and its regulation. Arch. Mikrobiol. 113, 131-138. doi: 10.1007/BF00428592

Boujelben, I., Gomariz, M., Martínez-García, M., Santos, F., Peña, A., López, C., et al. (2012). Spatial and seasonal prokaryotic community dynamics in ponds of increasing salinity of Sfax solar saltern in Tunisia. Antonie van Leeuwenhoek 101, 845-857. doi: 10.1007/s10482-012-9701-7 
Bowman, J. P., McCammon, S. A., Lewis, T., Skerratt, J. H., Brown, J. L., Nichols, D. S., et al. (1998). Psychroflexus torquis gen. nov., sp. nov., a psychrophilic species from Antarctic sea ice, and reclassification of Flavobacterium gondwanense (Dobson et al. 1993) as Psychroflexus gondwanense gen. nov., comb. nov. Microbiology 144, 1601-1609. doi: 10.1099/00221287-144-6-1601

Burns, D. G., Camakaris, H. M., Janssen, P. H., and Dyall-Smith, M. L. (2004). Cultivation of Walsby's square haloarchaeon. FEMS Microbiol. Lett. 238, 469-473. doi: 10.1016/j.femsle.2004.08.016

Camacho, C., Madden, T., Coulouris, G., Ma, N.,Tao, T., and Agarwala, R. (2008). BLAST Command Line Applications User Manual. Bookshelf ID: NBK 1763.

Chen, Y. G., Cui, X. L., Wang, Y. X., Tang, S. K., Zhang, Y. Q., Li, W. J., et al. (2009). Psychroflexus sediminis sp. nov., a mesophilic bacterium isolated from salt lake sediment in China. Int. J. Syst. Evol. Microbiol. 59, 569-573. doi: 10.1099/ijs.0.003269-0

Chimileski, S., Dolas, K., Naor, A., Gophna, U., and Papke, R. T. (2014). Extracellular DNA metabolism in Haloferax volcanii. Front. Microbiol. 5:57. doi: 10.3389/fmicb.2014.00057

Cole, J. R., Wang, Q., Fish, J. A., Chai, B., McGarrell, D. M., Sun, Y., et al. (2014). Ribosomal Database Project: data and tools for high throughput rRNA analysis. Nucleic Acids Res. 41, D633-D642. doi: 10.1093/nar/gkt1244

de la Haba, R. R., Sánchez-Porro, C., Márquez, M. C., and Ventosa, V. (2011). "Taxonomy of halophiles," in Extremophiles Handbook, eds K. Horikoshi, G. Antranikian, A. Bull, F. Robb, and K. Stetter (Heidelberg: Springer-Verlag), 255-308.

Dillon, J. G., Carlin, M., Gutierrez, A., Nguyen, V., and McLain, N. (2013). Patterns of microbial diversity along a salinity gradient in the Guerrero Negro solar saltern, Baja CA Sur, Mexico. Front. Microbiol. 4:399. doi: 10.3389/fmicb.2013.00399

Donachie, S. P., Bowman, J. P., and Alam, M. (2004). Psychroflexus tropicus sp. nov., an obligately halophilic Cytophaga-Flavobacterium-Bacteroides group bacterium from an Hawaiian hypersaline lake. Int. J. Syst. Evol. Microbiol. 54, 935-940. doi: 10.1099/ijs.0.02733-0

Dulau, N. (1983). Les Domaines Sédimentaires Préhalitiques des Marais Salants de la Région de Salin-de-Giraud (France) et de Santa Pola (Espagne). PhD. thesis, 3ème Cycle-Université Louis Pasteur, Strasbourg.

Elevi Bardavid, R., and Oren, A. (2008). Dihydroxyacetone metabolism in Salinibacter ruber and in Haloquadratum walsbyi. Extremophiles 12, 125-131. doi: 10.1007/s00792-007-0114-x

Felsenstein, J. (1989). PHYLIP - phylogeny inference package (Version 3.2). Cladistics 5, 164-166.

Fernández, A. B., Ghai, R., Martin-Cuadrado, A. B., Sanchez-Porro, C., RodriguezValera, F., and Ventosa, A. (2013). Metagenome sequencing of prokaryotic microbiota from two hypersaline ponds of a marine saltern in Santa Pola, Spain. Genome Announc. 1:e00933-13. doi: 10.1128/genomeA.00933-13

Fernández, A. B., Ghai, R., Martin-Cuadrado, A. B., Sánchez-Porro, C., RodriguezValera, F., and Ventosa, A. (2014a). Prokaryotic taxonomic and metabolic diversity of an intermediate salinity hypersaline habitat assessed by metagenomics. FEMS Microbiol. Ecol. doi: 10.1111/1574-6941.12329. (In press).

Fernández, A. B., León, M. J., Vera, B., Sanchez-Porro, C., and Ventosa, A. (2014b). Metagenomic sequence of prokaryotic microbiota from an intermediate salinity pond of a saltern in Isla Cristina, Spain. Genome Announc. 2:e00045-14. doi: 10.1128/genomeA.00045-14

Fox, E. M., and Mendz, G. L. (2006). Phosphonate degradation in microorganisms. Enzyme Microb. Technol. 40, 145-150. doi: 10.1016/j.enzmictec.2005.10.047

Ghai, R., Hernandez, C. M., Picazo, A., Mizuno, C. M., Ininbergs, K., Diez, B., et al. (2012). Metagenomes of Mediterranean coastal lagoons. Sci. Rep. 2:490. doi: 10.1038/srep00490

Ghai, R., Martin-Cuadrado, A. B., Molto, A. G., Heredia, I. G., Cabrera, R., Martin, J., et al. (2010). Metagenome of the Mediterranean deep chlorophyll maximum studied by direct and fosmid library 454 pyrosequencing. ISME J. 4, 1154-1166. doi: 10.1038/ismej.2010.44

Ghai, R., Pasic, L., Fernandez, A. B., Martin-Cuadrado, A. B., Mizuno, C. M., McMahon, K. D., et al. (2011). New abundant microbial groups in aquatic hypersaline environments. Sci. Rep. 1:135. doi: 10.1038/srep00135

Grant, W. D., Gemmell, R. T., and McGenity, T. J. (1998). "Halophiles," in Extremophiles: Microbial Life in Extreme Environment, eds K. Horikoshi and W. D. Grant (New York, NY: Wiley-Liss), 93-132.

Grant, W. D., Kamekura, M., McGenity, T. J., and Ventosa, A. (2001). "Class III. Halobacteria class. nov.," in Bergey's Manual of Systematic Bacteriology, 2nd Edn.,
Vol. 1, eds D. R. Boone, R. W. Castenholz, and G. M. Garrity (New York, NY: Springer), 294-301.

Grant, W. D., Pagaling, E., Marquez, M. C., Gutierrez, M. C., Cowan, D. A., Ma, Y., et al. (2011). "The hypersaline lakes of Inner Mongolia: the MGAtech Project," in Halophiles and Hypersaline Environments, eds A. Ventosa, A. Oren, and Y. Ma (Heidelberg: Springer), 65-107. doi: 10.1007/978-3-642-20198-1_4

Javor, B. J. (1989). "Solar salterns," in Hypersaline Environments: Microbiology and Biogeochemistry, ed B. Javor (Berlin: Springer-Verlag), 189-204.

Jørgensen, B. B. (1982). Ecology of the bacteria of the sulphur cycle with special reference to anoxic-oxic interface environments. Philos. Trans. R. Soc. Lond. B Biol. Sci. 298, 543-561. doi: 10.1098/rstb.1982.0096

Landry, J. C., and Jaccard, J. (1984). Chimie des eaux libres dans le marais salant de Santa-Pola, salina de Bras del Port. Rev. Geol. 38/39, 37-53.

Lê, S., Josse, J., and Husson, F. (2008). FactoMineR: an R package for multivariate analysis. J. Statist. Soft. 25, 1-18.

Legault, A. B., Lopez-Lopez, A., Alba-Casado, J. C., Doolittle, W. F., Bolhuis, H., Rodriguez-Valera, F., et al. (2006). Environmental genomics of "Haloquadratum walsbyi" in a saltern crystallizer indicates a large pool of accessory genes in an otherwise coherent species. BMC Genomics 7:171. doi: 10.1186/1471-216 4-7-171

Leon, M. J., Ghai, R., Fernandez, A. B., Sanchez-Porro, C., Rodriguez-Valera, F., and Ventosa, A. (2013). Draft genome of Spiribacter salinus M19-40, an abundant gammaproteobacterium in aquatic hypersaline environments. Genome Announc. 1:e00179-12. doi: 10.1128/genomeA.00179-12

López-Pérez, M., Ghai, R., Leon, M. J., Rodríguez-Olmos, A., Copa-Patiño, J. L., Soliveri, J., et al. (2013). Genomes of "Spiribacter," a streamlined, successful halophilic bacterium. BMC Genomics 14:787. doi: 10.1186/1471-2164-14-787

Lozupone, C. A., and Knight, R. (2007). Global patterns in bacterial diversity. Proc. Natl. Acad. Sci. U.S.A. 104, 11436-11440. doi: 10.1073/pnas.0611525104

Ludwig, W., Strunk, O., Westram, R., Richter, L., Meier, H., Yadhukumar., et al. (2004). ARB: a software environment for sequence data. Nucleic Acids Res. 32, 1363-1371. doi: 10.1093/nar/gkh293

Makhdoumi-Kakhki, A., Amoozegar, M. A., Kazemi, B., Pašić, L., and Ventosa, A. (2012). Prokaryotic diversity in Aran-Bidgol salt lake, the largest hypersaline playa in Iran. Microbes Environ. 27, 87-93. doi: 10.1264/jsme2.ME11267

Martín-Cuadrado, A. B., López-García, P., Alba, J. C., Moreira, D., Monticelli, L., Strittmatter, A., et al. (2007). Metagenomics of the deep Mediterranean, a warm bathypelagic habitat. PLOS ONE 2:e914. doi: 10.1371/journal.pone. 0000914

Moreno Mde, L., García, M. T., Ventosa, A., and Mellado, E. (2009). Characterization of Salicola sp. IC10, a lipase- and protease-producing extreme halophile. FEMS Microbiol. Ecol. 68, 59-71. doi: 10.1111/j.15746941.2009.00651.x

Naor, A., Lapierre, P., Mevarech, M., Papke, R. T., and Gophna, U. (2012). Low species barriers in halophilic archaea and the formation of recombinant hybrids. Curr. Biol. 22, 1444-1448. doi: 10.1016/j.cub.2012.05.056

Oh, D., Porter, K., Russ, B., Burns, D., and Dyall-Smith, M. (2010). Diversity of Haloquadratum and other haloarchaea in three, geographically distant, Australian saltern crystallizer ponds. Extremophiles 14, 161-169. doi: 10.1007/s00792-009-0295-6

Oren, A. (1988). Anaerobic degradation of organic compounds at high salt concentrations. Antonie van Leeuwenhoek 54, 267-277. doi: 10.1007/BF00443585

Oren, A. (1999). Bioenergetic aspects of halophilism. Microbiol. Mol. Biol. Rev. 63, 334-348.

Oren, A. (2008). Microbial life at high salt concentrations: phylogenetic and metabolic diversity. Saline Syst. 4:2. doi: 10.1186/1746-1448-4-2

Oren, A. (2013). Life at high salt concentrations, intracellular $\mathrm{KCl}$ concentrations, and acidic proteomes. Front. Microbiol. 4:315. doi: 10.3389/fmicb.2013.00315

Ouellette, M., Makkay, A. M., and Papke, R. T. (2013). Dihydroxyacetone metabolism in Haloferax volcanii. Front. Microbiol. 4:376. doi: 10.3389/fmicb. 2013.00376

Pagaling, E., Wang, H., Venables, M., Wallace, A., Grant, W. D., Cowan, D. A., et al. (2009). Microbial biogeography of six salt lakes in Inner Mongolia, China, and a salt lake in Argentina. Appl. Environ. Microbiol. 75, 5750-5760. doi: 10.1128/AEM.00040-09

Parnell, J. J., Rompato, G., Latta, L. C. 4th., Pfrender, M. E., Van Nostrand, J. D., He, Z., et al. (2010). Functional biogeography as evidence of gene transfer in hypersaline microbial communities. PLOS ONE 5:e12919. doi: 10.1371/journal.pone.0012919 
Pašić, L., Bartual, S. G., Ulrih, N. P., Grabnar, M., and Velikonja, B. H. (2005). Diversity of halophilic archaea in the crystallizers of an Adriatic solar saltern. FEMS Microbiol. Ecol. 54, 491-498. doi: 10.1016/j.femsec.2005.06.004

Pasić, L., Ulrih, N. P., Crnigoj, M., Grabnar, M., and Velikonja, B. H. (2007). Haloarchaeal communities in the crystallizers of two Adriatic solar salterns. Can. J. Microbiol. 53, 8-18. doi: 10.1139/w06-091

Paul, S., Bag, S. K., Das, S., Harvill, E. T., and Dutta, C. (2008). Molecular signature of hypersaline adaptation: insights from genome and proteome composition of halophilic prokaryotes. Genome Biol. 9:R70. doi: 10.1186/gb-2008-9-4-r70

Podell, S., Emerson, J. B., Jones, C. M., Ugalde, J. A., Welch, S., Heidelberg, K. B., et al. (2013). Seasonal fluctuations in ionic concentrations drive microbial succession in a hypersaline lake community. ISME J. 8, e61692. doi: 10.1038/ismej.2013.221

Ram Mohan, N., Fullmer, M. S., Makkay, A. M., Wheeler, R., Ventosa, A., Naor, A., et al. (2014). Evidence from phylogenetic and genome fingerprinting analyses suggests rapidly changing variation in Halorubrum and Haloarcula populations. Front. Microbiol. 5:143. doi: 10.3389/fmicb.2014.00143

Rice, P., Longden, I., and Bleasby, A. (2000). EMBOSS: the European Molecular Biology Open Software Suite. Trends Genet. 16, 276-277. doi: 10.1016/S01689525(00)02024-2

Rodríguez-Valera, F. (1988). "Characteristics and microbial ecology of hypersaline environments," in Halophilic Bacteria, ed F. Rodríguez-Valera (Boca Raton, FL: CRC Press), 3-30.

Rodríguez-Valera, F. (1993). "The biology of halophilic bacteria," in Introduction to Saline Environments, eds R. H. Vreeland and L. Hochstein (Boca Raton, FL: CRC Press), 1-23.

Rodríguez-Valera, F., Ruiz-Berraquero, F., and Ramos-Cormenzana, A. (1981). Characteristics of the heterotrophic bacterial populations in hypersaline environments of different salt concentrations. Microb. Ecol. 7, 235-243. doi: 10.1007/BF02010306

Rodríguez-Valera, F., Ventosa, A., Juez, G., and Imhoff, J. F. (1985). Variation of environmental features and microbial populations with salt concentrations in a multipond saltern. Microb. Ecol. 11, 107-115. doi: 10.1007/ BF02010483

Schapira, M., Buscot, M. J., Leterme, S. C., Pollet, T., Chapperon, C., and Seuront, L. (2009). Distribution of heterotrophic bacteria and virus-like particles along a salinity gradient in a hypersaline coastal lagoon. Aquat. Microb. Ecol. 54, 171-183. doi: 10.3354/ame01262

Seiler, H., Bleicher, A., Busse, H. J., Hüfner, J., and Scherer, S. (2012). Psychroflexus halocasei sp. nov., isolated from a microbial consortium on a cheese. Int. J. Syst. Evol. Microbiol. 62, 1850-1856. doi: 10.1099/ijs.0.034801-0

Shinagawa, H., Makino, K., Amemura, M., and Nakata, A. (1987). "Structure and function of the regulatory genes for the phosphate regulon, in Escherichia coli," in Phosphate Metabolism and Cellular Regulation in Microorganisms, eds A. Torriani-Gorini, F. G. Rothman, S. Silver, A. Wright, and E. Yagil (Washington, DC: American Society for Microbiology), 20-25.

Soppa, J. (2006). From genomes to function: haloarchaea as model organisms. Microbiology 152, 585-590. doi: 10.1099/mic.0.28504-0
Torriani, A., and Ludtke, D. N. (1985). "The pho regulon of Escherichia coli," in The Molecular Biology of Bacterial Growth, eds M. Schaechter, F. C. Neidhardt, J. Ingraham, and N. O. Kjeldgaard (Boston, MA: Jones and Bartlett Publishers), 224-242.

UniProt Consortium. (2014). Activities at the Universal Protein Resource (UniProt). Nucleic Acids. Res. 42, D191-D198. doi: 10.1093/nar/gkt1140

Ventosa, A. (2006). "Unusual micro-organisms from unusual habitats: hypersaline environments," in Prokaryotic Diversity: Mechanism and Significance, eds N. A. Logan, H. M. Lappin-Scott, and P. C. F. Oyston (Cambridge: Cambridge University Press), 223-253.

Ventosa, A., Mellado, E., Sanchez-Porro, C., and Marquez, M. C. (2008). "Halophilic and halotolerant micro-organisms from soils," in Microbiology of Extreme Soils, eds P. Dion and C. S. Nautiyal (Berlin: Springer-Verlag), 87-115.

Walsh, D. A., Papke, R. T., and Doolittle, W. F. (2005). Archaeal diversity along a soil salinity gradient prone to disturbance. Environ. Microbiol. 7, 1655-1666. doi: 10.1111/j.1462-2920.2005.00864.x

Wanner, B. L. (1987). "Phosphate regulation of gene expression in Escherichia coli," in Escherichia coli and Salmonella typhimurium: Cellular and Molecular Biology, Vol. 2, eds F. C. Neidhardt, J. Ingraham, K. B. Low, B. Magasanik, M. Schaechter, and H. E. Umbarger (Washington, DC: American Society for Microbiology), 1326-1333.

Wanner, B. L. (1993). Gene regulation by phosphate in enteric bacteria. J. Cell. Biochem. 51, 47-54. doi: 10.1002/jcb.240510110

Yoon, J. H., Kang, S. J., Jung, Y. T., and Oh, T. K. (2009). Psychroflexus salinarum sp. nov., isolated from a marine solar saltern. Int. J. Syst. Evol. Microbiol. 59, 2404-2407. doi: 10.1099/ijs.0.008359-0

Zhaxybayeva, O., Stepanauskas, R., Mohan, N. R., and Papke, R. T. (2013). Cell sorting analysis of geographically separated hypersaline environments. Extremophiles 17, 265-275. doi: 10.1007/s00792-013-0514-z

Conflict of Interest Statement: The authors declare that the research was conducted in the absence of any commercial or financial relationships that could be construed as a potential conflict of interest.

Received: 27 February 2014; accepted: 12 April 2014; published online: 08 May 2014. Citation: Fernández AB, Vera-Gargallo B, Sánchez-Porro C, Ghai R, Papke RT, Rodriguez-Valera F and Ventosa A (2014) Comparison of prokaryotic community structure from Mediterranean and Atlantic saltern concentrator ponds by a metagenomic approach. Front. Microbiol. 5:196. doi: 10.3389/fmicb.2014.00196

This article was submitted to Extreme Microbiology, a section of the journal Frontiers in Microbiology.

Copyright (c) 2014 Fernández, Vera-Gargallo, Sánchez-Porro, Ghai, Papke, Rodriguez-Valera and Ventosa. This is an open-access article distributed under the terms of the Creative Commons Attribution License (CC BY). The use, distribution or reproduction in other forums is permitted, provided the original author(s) or licensor are credited and that the original publication in this journal is cited, in accordance with accepted academic practice. No use, distribution or reproduction is permitted which does not comply with these terms. 